\title{
Secondary Metabolites from Asphodelus aestivus
}

\author{
İhsan Çalış ${ }^{\mathrm{a}}$, S. Serap Birincioğlu ${ }^{\mathrm{b}}$, Hasan Kırmızıbekmez ${ }^{\mathrm{a}}$, Bernhard Pfeiffer ${ }^{\mathrm{c}}$, \\ and Jörg Heilmann ${ }^{\text {d }}$ \\ ${ }^{a}$ Department of Pharmacognosy, Faculty of Pharmacy, Hacettepe University, 06100 Ankara, Turkey \\ b Adnan Menderes University, Faculty of Veterinary Medicine, Department of Pathology, \\ 09016 Aydın, Turkey \\ c ETH-Zürich, Institute of Pharmaceutical Sciences, \\ Hönggerberg, HCI H 492.4, CH-8093 Zürich, Switzerland \\ d Universität Regensburg, Institut für Pharmazie, Lehrstuhl Pharmazeutische Biologie, \\ Universitätsstraße 31, D-93053 Regensburg, Germany
}

Reprint requests to Dr. İhsan Çalış. Fax: +90 312311 4777. E-mail: icalis@ hacettepe.edu.tr

Z. Naturforsch. 61b, 1304 - 1310 (2006); received March 21, 2006

Together with ten well known compounds, the quinic acid derivative chlorogenic acid, the nucleoside adenosine, two amino acids, tryptophan and phenylalanine, the anthraquinone derivatives, aloemodin, aloemodin acetate and chyrosphanol 1-O-gentiobioside, the flavon $\mathrm{C}$-glycosides, isovitexin, isoorientin and isoorientin $4^{\prime}-O-\beta$-glucopyranoside, as well as two new acylated isoorientin derivatives, 6"- $O$-(malonyl)-isoorientin and 6"-O-[(S)-3-hydroxy-3-methylglutaroyl]-isoorientin, were isolated from the water soluble part of the methanolic extract of the fresh leaves of Asphodelus aestivus. All compounds were structurally identified by spectroscopic methods, including UV, MS, and NMR (1D and 2D) spectroscopy. Among the compounds isolated, chlorogenic acid and isoorientin were found to be the main compounds of the methanolic extract.

Key words: Asphodelus aestivus, Liliaceae, Secondary Metabolites, Acylated Flavone C-Glycosides

\section{Introduction}

Asphodelus aestivus Brot. is one of the three Asphodelus L. species represented in the flora of Turkey [1]. A severe neurologic syndrome accompanied by intense neuronal pigmentation in sheep in Turkey was observed after ingestion of $A$. aestivus. The disease was characterized by neurological signs, such as paresis, ataxia and convulsions and the pathological findings were recently reported [2]. Previous phytochemical investigations performed on Asphodelus species resulted in the isolation of anthranoides, flavonoids and triterpenes [3-6]. However, all compounds have been isolated from the tubers of Asphodelus species and not from the ingested aerial parts. These observations prompted us to investigate for the secondary metabolites of the fresh leaves of A. aestivus with the aim to isolate important representatives for further biological in vitro and in vivo testing. Thus, we report in the present study on the isolation of two new flavone C-glycosides, 6"-O-(malonyl)-isoorientin (11) and 6"$O$-[(S)-3-hydroxy-3-methylglutaroyl]-isoorientin (12). Besides ten known compounds, namely three anthranoides (1,8-dihydroxy-anthraquinones), three known flavone $\mathrm{C}$-glycosides, one nucleoside, two amino acids and a quinic acid derivative were isolated.

\section{Experimental Section}

General experimental procedures

UV spectra were recorded on a HP Agilent 8453 spectrophotometer. Optical rotations were measured on a Rudolph Autopol IV polarimeter. 1D and 2D NMR spectra were recorded on Bruker AMX (Avance) 300, 400 and $600 \mathrm{MHz}$ spectrometers at $295 \mathrm{~K}$ and referenced against the respective residual non deuterated solvent (see Tables 1 and 2). ESIMS spectra were measured on a ThermoQuest Finnigan 7000 with a spray voltage of $4 \mathrm{kV}$. HR-LSIMS were recorded on a Finnigan MAT $95\left(\mathrm{Cs}^{+}, 15 \mathrm{kV}\right)$. TLC analyses were carried out on silica gel $60 \mathrm{~F}_{254}$ precoated plates (O.2 mm; Merck, Darmstadt). $1 \%$ Vanillin/ $\mathrm{H}_{2} \mathrm{SO}_{4}$ was used as detection reagent. For medium-pressure liquid chromatographic (MPLC) separations, a Büchi B pump, a LKB 17000 Minirac fraction collector, a Rheodyne injector, and Büchi columns (column dimensions $2.6 \times 46 \mathrm{~cm}$, and $1.8 \times 35 \mathrm{~cm}$ ) were used. Silica gel 60 (0.063-0.200 mm; Merck, Darmstadt), Polyamide (Fluka) and Sephadex LH-20 (Fluka) were utilized for open column chromatography (CC). LiChroprep RP-18 (25-40 $\mu \mathrm{m}$, Merck) material was used for MPLC. 
Table 1. The ${ }^{1} \mathrm{H}$ NMR spectroscopic data for flavon C-glycosides 8-12 $(\delta \mathrm{ppm}, \mathrm{m}, J$ in $\mathrm{Hz})$.

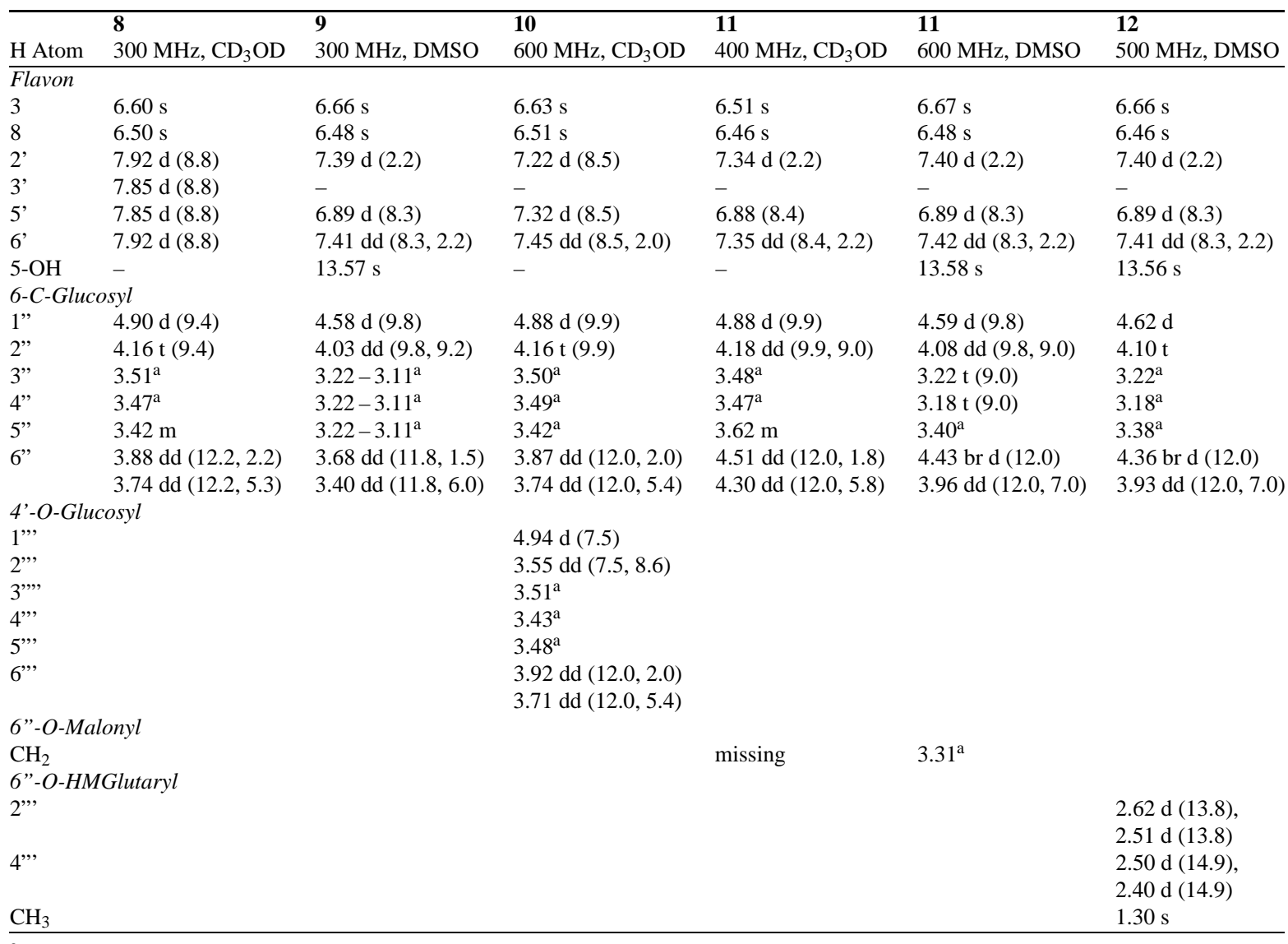

${ }^{\mathrm{a}}$ Unclear signal pattern due to overlapping.

\section{Plant material}

Asphodelus aestivus Brot. (Liliaceae) was collected from Kusadasi, Aydın, W. Anatolia, in Turkey at August 20, 2002. The plant material was identified by Dr. Bengi Erdağ (Department of Biology, Faculty of Arts and Sciences, University of Adnan Menderes, Aydin, Turkey). The voucher specimen (AYDN T-29) has been deposited at the Herbarium of the AYDN, Faculty of Science \& Arts, Adnan Menderes University, Aydın, Turkey.

\section{Extraction and isolation}

The fresh leaves of A. aestivus (650 g) were cut into small pieces and macerated with $\mathrm{MeOH}(51)$ at r.t. for three days. The methanolic extract was evaporated to dryness in vacuo. The crude extract was suspended in $\mathrm{H}_{2} \mathrm{O}$ and partitioned against $\mathrm{CH}_{2} \mathrm{Cl}_{2}$. The lyophilised $\mathrm{H}_{2} \mathrm{O}$ extract $(28.3 \mathrm{~g}$ ) was divided into two equal parts and each was subjected to $\mathrm{C}_{18}$-Medium Pressure Liquid Chromatography $\left(\mathrm{C}_{18}\right.$-MPLC, column dimension: $2.6 \times 46 \mathrm{~cm}$ ) with $\mathrm{H}_{2} \mathrm{O}, 25 \% \mathrm{MeOH}$,
$50 \% \mathrm{MeOH}$ and $\mathrm{MeOH}$ as eluents to obtain four main fractions, A - D. Similar fractions obtained from the two columns were combined after TLC control. Fraction B (1200 mg) was likewise applied to $\mathrm{C}_{18}$-MPLC (column dimensions: $2.6 \times 46 \mathrm{~cm})$ using a $\mathrm{MeOH}$ gradient $(0-50 \%)$ to obtain 1 (chlorogenic acid, $350 \mathrm{mg}$ ) as well as two subfractions, $\mathrm{B}_{1-2}$. Purification of subfraction $\mathrm{B}_{1}(52 \mathrm{mg})$ by $\mathrm{CC}$ on $\mathrm{SiO}_{2}$ gel (EtOAc-MeOH- $\mathrm{H}_{2} \mathrm{O}, 100: 10: 5$ ) furnished 3 (tryptophan, $5 \mathrm{mg}$ ) and 4 (phenylalanine, $9 \mathrm{mg}$ ). Repeated CC of subfraction $\mathrm{B}_{2}\left(38 \mathrm{mg}\right.$ ) on a $\mathrm{SiO}_{2}$ gel (EtOAc-MeOH$\mathrm{H}_{2} \mathrm{O}, 100: 10: 5$ ) gave 2 (adenosine, $16 \mathrm{mg}$ ). Fraction $\mathrm{C}$ (1030 mg) was subjected to $\mathrm{C}_{18}$-MPLC (column dimensions: $2.4 \times 32 \mathrm{~cm}$ ), and eluted with $\mathrm{MeOH}-\mathrm{H}_{2} \mathrm{O}$ mixtures $(25-$ $100 \% \mathrm{MeOH})$ to yield seven fractions, $\mathrm{C}_{1-7}$. Repeated CC of fraction $\mathrm{C}_{2}(94 \mathrm{mg})$ on $\mathrm{SiO}_{2}$ gel $\left(\mathrm{CH}_{2} \mathrm{Cl}_{2}-\mathrm{MeOH}-\mathrm{H}_{2} \mathrm{O}\right.$, $80: 20: 2$ to $60: 40: 10)$ and Sephadex LH-20 (MeOH), respectively gave 10 (isoorientin 4'- $O$-glucopyranoside, $4 \mathrm{mg}$ ). Fraction $\mathrm{C}_{4}(118 \mathrm{mg})$ was rechromatographed on $\mathrm{a} \mathrm{SiO}_{2}$ column (EtOAc-MeOH-H ${ }_{2} \mathrm{O}, 100: 17: 13$ ) to afford 9 (isoorientin, $62 \mathrm{mg})$. Compounds $12\{6$ "-O-[(S)-3-hydroxy-3- 
Table 2. The ${ }^{13} \mathrm{C}$ NMR spectroscopic data for flavon C-glycosides, $8-12(\delta \mathrm{ppm})$.

\begin{tabular}{|c|c|c|c|c|c|c|}
\hline & $\overline{8}$ & 9 & 10 & 11 & 11 & 12 \\
\hline C Atom & MeOD & DMSO-d $_{6}$ & MeOD & $\mathrm{MeOD}$ & DMSO-d $_{6}$ & $\mathrm{DMSO}^{-\mathrm{d}_{6}}$ \\
\hline \multicolumn{7}{|l|}{ Flavon } \\
\hline & Apigenin & Luteolin & Luteolin & Luteolin & Luteolin & Luteolin \\
\hline 2 & 166.4 & 163.6 & 165.4 & 166.2 & 163.6 & 163.8 \\
\hline 3 & 104.1 & 102.8 & 105.3 & 104.0 & 102.7 & 102.8 \\
\hline 4 & 184.2 & 181.9 & 184.0 & 184.0 & 181.8 & 181.4 \\
\hline 5 & 163.0 & 160.7 & 162.1 & 162.1 & 160.5 & 161.2 \\
\hline 6 & 109.4 & 108.9 & 109.5 & 108.8 & 108.4 & 108.5 \\
\hline 7 & 165.2 & 163.3 & 165.0 & 164.9 & 163.1 & 163.6 \\
\hline 8 & 95.4 & 93.5 & 95.4 & 95.2 & 93.4 & 93.4 \\
\hline 9 & 158.9 & 156.2 & 158.7 & 158.8 & 156.1 & 156.2 \\
\hline 10 & 105.3 & 103.4 & 105.4 & 105.2 & 103.3 & 103.3 \\
\hline $1^{\prime}$ & 123.3 & 121.4 & 127.1 & 123.6 & 121.3 & 121.4 \\
\hline $2^{\prime}$ & 129.6 & 113.3 & 115.0 & 114.2 & 113.2 & 113.3 \\
\hline $3^{\prime}$ & 117.2 & 145.7 & 148.7 & 147.0 & 145.6 & 145.7 \\
\hline $4^{\prime}$ & 162.2 & 149.7 & 150.1 & 151.0 & 149.6 & 149.7 \\
\hline $5^{\prime}$ & 117.2 & 116.0 & 118.0 & 116.8 & 116.0 & 116.0 \\
\hline $6^{\prime}$ & 129.6 & 119.0 & 119.9 & 120.3 & 118.9 & 118.9 \\
\hline \multicolumn{7}{|l|}{$5-\mathrm{OH}$} \\
\hline \multicolumn{7}{|l|}{ 6-Glucosyl } \\
\hline $1 "$ & 75.5 & 73.1 & 75.3 & 75.4 & 72.9 & 73.1 \\
\hline $2 "$ & 72.8 & 70.6 & 72.6 & 72.4 & 69.8 & 69.9 \\
\hline $3 "$ & 82.8 & 81.6 & 82.7 & 79.9 & 78.5 & 78.7 \\
\hline $4 "$ & 72.0 & 70.2 & 71.9 & 71.8 & 70.3 & 70.5 \\
\hline $5 "$ & 80.3 & 79.0 & 80.2 & 79.7 & 78.0 & 78.1 \\
\hline $6 "$ & 63.0 & 61.5 & 62.9 & 65.9 & 65.2 & 64.1 \\
\hline \multicolumn{7}{|l|}{ 4'-O-Glucosyl } \\
\hline 1 '" & & & 103.2 & & & \\
\hline $2 "$ & & & 74.8 & & & \\
\hline $3 "$, & & & 78.6 & & & \\
\hline $4 "$ & & & 71.3 & & & \\
\hline $5 "$ & & & 77.6 & & & \\
\hline $6 "$ & & & 62.5 & & & \\
\hline \multicolumn{7}{|l|}{ 6"-O-Malonyl } \\
\hline $\mathrm{CH}_{2}$ & & & & $\operatorname{missing}^{\mathrm{a}}$ & 41.5 & \\
\hline RCOOR' & & & & 168.8 & 167.9 & \\
\hline $\mathrm{RCOOH}$ & & & & 170.8 & 167.0 & \\
\hline \multicolumn{7}{|c|}{ 6"-O-HMGlutaroyl } \\
\hline 1"' (RCOOR') & & & & & & 170.5 \\
\hline $2 "$ & & & & & & 45.3 \\
\hline $3 "$, & & & & & & 69.0 \\
\hline $4 "$, & & & & & & 45.4 \\
\hline $5 ",(\mathrm{RCOOH})$ & & & & & & 172.6 \\
\hline $\mathrm{Me}$ & & & & & & 27.3 \\
\hline
\end{tabular}

a The signal is missing due to overlapping by solvent signal.

methylglutaroyl]-isoorientin, $10 \mathrm{mg}\}$ and $\mathbf{8}$ (isovitexin, $14 \mathrm{mg}$ ) were purified from fraction $\mathrm{C}_{6}(104 \mathrm{mg})$ by CC using Sephadex $\mathrm{LH}-20(\mathrm{MeOH})$ and $\mathrm{SiO}_{2}$ gel (EtOAc-MeOH$\mathrm{H}_{2} \mathrm{O}, 100: 15: 0$ to $100: 17: 13$ ) as stationary phase. Fraction $\mathrm{D}(152 \mathrm{mg})$ was applied to $\mathrm{CC}$ on $\mathrm{SiO}_{2}$ gel using a gradient of $\mathrm{CH}_{2} \mathrm{Cl}_{2}-\mathrm{MeOH}-\mathrm{H}_{2} \mathrm{O}(80: 20: 1$ to $50: 50: 5)$ to give 7 (chrysophanol 1- $O$-gentiobioside, $8 \mathrm{mg}$ ).

In order to isolate the phenolic compounds, which were present in small amounts in the previous extract, we increased the amount of the material $(2 \mathrm{~kg})$ and extracted with $\mathrm{MeOH}(81)$. The methanolic extract was evaporated to dry- ness in vacuo. The crude extract was suspended in $\mathrm{H}_{2} \mathrm{O}$ and partitioned against $\mathrm{CH}_{2} \mathrm{Cl}_{2}$. The lyophilised $\mathrm{H}_{2} \mathrm{O}$ extract (75 g) was mounted on a column with polyamide as stationary phase. Elution with $\mathrm{H}_{2} \mathrm{O}$ and the increasing amounts of $\mathrm{MeOH}$ in $\mathrm{H}_{2} \mathrm{O}(10-100 \%)$ yielded nine main fractions, AI. Fraction $\mathrm{G}(2.317 \mathrm{~g})$ was dissolved in $\mathrm{H}_{2} \mathrm{O}$ and extracted with EtOAc. The lyophilised EtOAc extract $(1 \mathrm{~g})$ was applied to $\mathrm{CC}$ on $\mathrm{SiO}_{2}$ gel using mixtures of EtOAc-MeOH$\mathrm{H}_{2} \mathrm{O}(100: 10: 2$ to $100: 20: 15)$ as mobile phase to give four subfractions, $\mathrm{G}_{1-4}$. Subfraction $\mathrm{G}_{1}(400 \mathrm{mg})$ was fractionated by $\mathrm{CC}$ over $\mathrm{SiO}_{2}$ gel to obtain two subfractions, 
$\mathrm{G}_{1 \mathrm{a}-\mathrm{b}}$. Compounds 6 (aloe-emodin acetate, $5 \mathrm{mg}$ ) and $\mathbf{5}$ (aloe-emodin, $7 \mathrm{mg}$ ) were purified by using the same method (CC on Sephadex LH-20, MeOH) from fractions $\mathrm{G}_{1 \mathrm{a}}(90 \mathrm{mg}$ ) and $\mathrm{G}_{1 \mathrm{~b}}(80 \mathrm{mg})$ respectively. Fraction $\mathrm{I}(250 \mathrm{mg})$ was applied to a polyamide column utilising $\mathrm{CH}_{2} \mathrm{Cl}_{2}-\mathrm{MeOH}-$ acetone-ethylmethylketone $(3: 2: 1: 1)$ to give two subfractions, $\mathrm{I}_{1-2} .6$ "- $O$-(Malonyl)-isoorientin $(\mathbf{1 1}, 15 \mathrm{mg}$ ) was purified from subfraction $\mathrm{I}_{1}(114 \mathrm{mg})$ by $\mathrm{CC}$ on Sephadex LH-20 (cyclohexane-aceton- $\mathrm{CH}_{2} \mathrm{Cl}_{2}-\mathrm{MeOH}, 1: 1: 1: 2$ ).

\section{Isovitexin $(8)$}

Amorphous yellow powder. - UV/vis $(\mathrm{MeOH}): \lambda_{\max }=$ 270, 302 and $335 \mathrm{~nm} .-{ }^{1} \mathrm{H}$ NMR (300 MHz, CD 3 OD): Table 1. ${ }^{13} \mathrm{C}$ NMR (75 MHz, $\mathrm{CD}_{3} \mathrm{OD}$ ): Table 2. - MS (ESI): $m / z=433[\mathrm{M}+\mathrm{H}]^{+}$and $431[\mathrm{M}-\mathrm{H}]^{-}$, calcd. for $\mathrm{C}_{21} \mathrm{H}_{20} \mathrm{O}_{10}$.

\section{Isoorientin (9)}

Amorphous yellow powder. - UV/vis $(\mathrm{MeOH}): \lambda_{\max }=$ 255, 270 and $350 \mathrm{~nm} .-{ }^{1} \mathrm{H}$ NMR (300 MHz, DMSO-d 6 ): Table 1. $-{ }^{13} \mathrm{C}$ NMR (75 MHz, DMSO-d 6 ): Table 2. MS (ESI): $m / z=449[\mathrm{M}+\mathrm{H}]^{+}$and $447[\mathrm{M}-\mathrm{H}]^{-}$, calcd. for $\mathrm{C}_{21} \mathrm{H}_{20} \mathrm{O}_{11}$.

\section{Isoorientin 4'-O-glucopyranoside (10)}

Amorphous yellow powder. $-\mathrm{UV} / \mathrm{vis}(\mathrm{MeOH}): \lambda_{\max }=$ 240, 273 and $335 \mathrm{~nm} .-{ }^{1} \mathrm{H}$ NMR (600 MHz, CD 3 OD): Table 1. $-{ }^{13} \mathrm{C}$ NMR (150 MHz, $\left.\mathrm{CD}_{3} \mathrm{OD}\right)$ : Table 2. - MS (ESI): $\mathrm{m} / z=611[\mathrm{M}+\mathrm{H}]^{+}, 633[\mathrm{M}+\mathrm{Na}]^{+}, 1243[2 \mathrm{M}+\mathrm{Na}]^{+}$and 609 $[\mathrm{M}-\mathrm{H}]^{-}, 1219[2 \mathrm{M}-\mathrm{H}]^{-}$, calcd. for $\mathrm{C}_{27} \mathrm{H}_{30} \mathrm{O}_{16}$.

\section{6"-O-(Malonyl)-isoorientin (11)}

Amorphous yellow powder. $-[\alpha]_{\mathrm{D}}^{25}+10.9(c 0.1, \mathrm{MeOH})$. - UV/vis $(\mathrm{MeOH}): \lambda_{\max }=211,255(\mathrm{sh}), 271,348 \mathrm{~nm}$. ${ }^{1} \mathrm{H}$ NMR (600 MHz, DMSO-d 6 ): Table $1 .-{ }^{13} \mathrm{C}$ NMR (150 MHz, DMSO-d $\mathrm{d}_{6}$ ): Table 2. - MS (HR-LSI): $\mathrm{m} / \mathrm{z}$ found $535.1087[\mathrm{M}+\mathrm{H}]^{+}$, calcd. $535.1088\left(\mathrm{C}_{24} \mathrm{H}_{22} \mathrm{O}_{14}\right) .-\mathrm{MS}$ (ESI): $m / z=535[\mathrm{M}+\mathrm{H}]^{+}$and $533[\mathrm{M}-\mathrm{H}]^{-}$.

6"-O-[(S)-3-hydroxy-3-methylglutaroyl]-isoorientin (12)

Amorphous yellow powder. $-[\alpha]_{\mathrm{D}}^{25}+2.9(c 0.1, \mathrm{MeOH})$. - UV/vis $(\mathrm{MeOH}): \lambda_{\max }=210,255(\mathrm{sh}), 271,340 \mathrm{~nm}$. ${ }^{1} \mathrm{H}$ NMR (500 MHz, DMSO-d 6 ): Table $1 .-{ }^{13} \mathrm{C}$ NMR (125 MHz, DMSO-d ${ }_{6}$ ): Table 2. - MS (HR-LSI): $\mathrm{m} / z$ found $593.1497[\mathrm{M}+\mathrm{H}]^{+}$, calcd. $593.1506\left(\mathrm{C}_{27} \mathrm{H}_{28} \mathrm{O}_{15}\right)$. - MS (ESI): $m / z=593[\mathrm{M}+\mathrm{H}]^{+}$and $591[\mathrm{M}-\mathrm{H}]^{-}$.

\section{Results and Discussion}

Chromatographic studies on the water soluble part of the methanolic extract of fresh leaves of $A s$ -<smiles>O=C(O)C1CC(O)C(O)(C(=O)O)CC(O)C1O</smiles><smiles>O=C1c2cccc(O)c2C(=O)c2c(O)cc(CO)cc21</smiles>

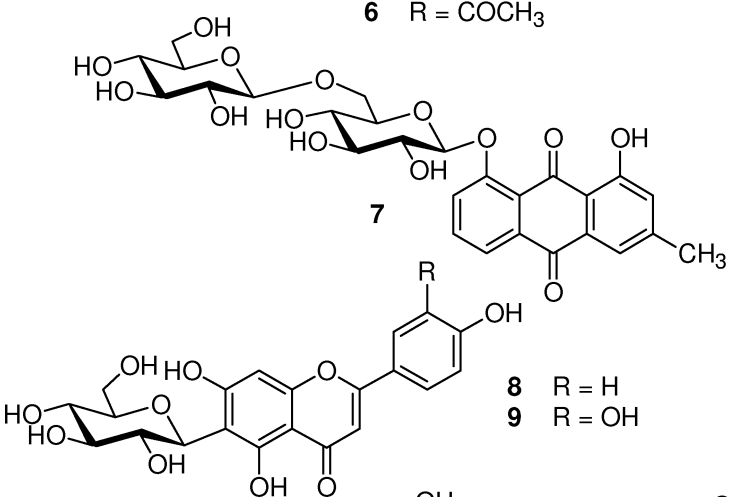<smiles>C[C@@](O)(CCO)CC(=O)OCCC(O)[C@H](O)[C@H](O)OC(O)c1c(O)cc2oc(-c3ccc(O)c(O)c3)cc(=O)c2c1O</smiles>

phodelus aestivus yielded compounds 1-12, chlorogenic acid (1), adenosine (2), tryptophan (3), phenylalanine (4), aloe-emodin (5), aloe-emodin acetate (6), chyrosphanol 1-O-gentiobioside (7), and five flavon C-glycosides, isovitexin (8), isoorientin (9) and isoorientin 4'- $O$ - $\beta$-glucopyranoside (10), 6"- $O$ (malonyl)-isoorientin (11) and 6"- $O-[(S)$-3-hydroxy-3methylglutaroyl]-isoorientin (12).

The main components of the extract were a series of $\beta$-D-glucopyranosides of apigenin and luteolin show- 
ing a $\mathrm{C}-\mathrm{C}$ linkage to $\mathrm{C}-6$ of the flavon nucleus $(\mathbf{8}-\mathbf{1 2})$. All of them were obtained as yellow amorphous solids and the UV data supported their flavonoid structure. The ${ }^{1} \mathrm{H}$ NMR spectra of compounds $8-12$ showed two singlets corresponding to the protons of $\mathrm{H}-3$ and $\mathrm{H}-8$ in rings $\mathrm{C}$ and $\mathrm{A}$ of a flavone, respectively (Table 1). All ${ }^{13} \mathrm{C}$ NMR spectra exhibited a signal between $\delta=73.0$ and 76.0 characteristic to an anomeric carbon (C-1") of a glucose moiety C-C connected to the aglycone (Table 2 ). The site of the $\mathrm{C}$-glycosidation position on the ring $\mathrm{A}$ in 8-12 was established to be at C- 6 of the flavone moiety by the appearance of long-range ${ }^{1} \mathrm{H},{ }^{13} \mathrm{C}$-correlations between the glucosyl anomeric proton (H-1") and the carbon signals assigned as $\mathrm{C}-5(\sim \delta=161.0), \mathrm{C}-6(\sim \delta=108.5)$ and $\mathrm{C}-7(\sim \delta=163.5)$ in the ${ }^{1} \mathrm{H},{ }^{13} \mathrm{C}$ HMBC experiments. The NMR signals of the sugar units and the flavonoids were completely assigned from ${ }^{1} \mathrm{H},{ }^{13} \mathrm{C},{ }^{1} \mathrm{H},{ }^{1} \mathrm{H}$ COSY, ${ }^{1} \mathrm{H},{ }^{13} \mathrm{C}$ HSQC and ${ }^{1} \mathrm{H},{ }^{13} \mathrm{C}$ HMBC experiments.

In addition to common observations mentioned above, the ${ }^{1} \mathrm{H}$ NMR spectrum of compound $\mathbf{8}$ (Table 1) showed additional signals of two sets of doublets as an AA'BB' system at $\delta=7.92$ and 7.85 (each $2 \mathrm{H}$, $\mathrm{d}, J=8.8 \mathrm{~Hz}$ ), due to the protons of $\mathrm{H}-2^{\prime} / \mathrm{H}-6^{\prime}$ and $\mathrm{H}-3$ '/H-5' of ring $\mathrm{B}$, respectively. These clearly supported the presence of an apigenin type flavone moiety for $\mathbf{8}$. The ${ }^{13} \mathrm{C}$ NMR resonances (Table 2 ) assigned for $\mathbf{8}$ were also in good agreement to literature values $[7,8]$. Based on this observations, the structure of $\mathbf{8}$ was established as isovitexin.

In the ${ }^{1} \mathrm{H}$ NMR spectrum of compound 9 , the signals of ring $\mathrm{B}$ resonated as an $\mathrm{ABX}$ system at $\delta=7.39(1 \mathrm{H}$, d, $J=2.2 \mathrm{~Hz}, \mathrm{H}-2$ ') 6.89 (1H, d, $J=8.3 \mathrm{~Hz}, \mathrm{H}-5$ '), and $7.41(1 \mathrm{H}, \mathrm{dd}, J=8.3$ and $2.2 \mathrm{~Hz}, \mathrm{H}-6$ ' $)$ indicating the presence of a 1,3,4-trisubstitution on ring $\mathrm{B}$ as in luteolin. The ${ }^{13} \mathrm{C}$ NMR resonances (Table 2) of 9 were in good agreement with those reported for isoorientin $[7,8]$. The molecular formula of 9 was determined as $\mathrm{C}_{21} \mathrm{H}_{20} \mathrm{O}_{11}$ by NMR data (Tables 1 and 2) and ESIMS which showed pseudomolecular ion peaks at $m / z=449[\mathrm{M}+\mathrm{H}]^{+}$and $447[\mathrm{M}-\mathrm{H}]^{-}$confirming the proposed structure.

The ESIMS spectra of compound $\mathbf{1 0}$ showed quasimolecular ion peaks at $\mathrm{m} / z=611[\mathrm{M}+\mathrm{H}]^{+}, 633$ $[\mathrm{M}+\mathrm{Na}]^{+}$and $1243[2 \mathrm{M}+\mathrm{Na}]^{+}$in the positive and $609[\mathrm{M}-\mathrm{H}]^{-}$in the negative mode and provided together with the ${ }^{13} \mathrm{C}$ NMR data a molecular formula of $\mathrm{C}_{27} \mathrm{H}_{30} \mathrm{O}_{16}$. Its ${ }^{1} \mathrm{H}$ and ${ }^{13} \mathrm{C}$ NMR spectra exhibited a second anomeric proton signal and a corresponding carbon resonance at $\delta_{\mathrm{H}}=4.94(\mathrm{~d}, J=7.5 \mathrm{~Hz}, \mathrm{H}-1$ "') and $\delta_{\mathrm{C}}=103.2\left(\mathrm{CH}, \mathrm{C}-1\right.$ "'), respectively. The ${ }^{1} \mathrm{H}$ and ${ }^{13} \mathrm{C}$ NMR resonances (Tables 1 and 2 ) assigned to the second sugar unit indicated the presence of an additional O-linked glucose. Based on the coupling constant of the anomeric proton $(J=7.5 \mathrm{~Hz})$, its configuration was found to be $\beta$. The chemical shifts of the $\mathrm{ABX}$ system attributed to the ring $\mathrm{B}$ were differing from those of isoorientin (9) and its derivatives (1112) which have no glucosidation on ring $B$. A downfield shift of $\sim 0.4 \mathrm{ppm}$ observed for $\mathrm{H}-5^{\prime}(\delta=7.32$, $\mathrm{d}, J=8.3 \mathrm{~Hz}$ ) indicated the hydroxy group at C-4' as glycosidation site of the second glucose moiety. This assumption was verified by a HMBC experiment showing the long-range correlation between the anomeric proton $(\delta=4.94)$ of the glucose and C-4' $(\delta=150.1)$. Based on these results, the structure of $\mathbf{1 0}$ was established as isoorientin 4'- $O$ - $\beta$-glucopyranoside [9-11].

HR-LSIMS of 11 showed a pseudomolecular ion $[\mathrm{M}+\mathrm{H}]^{+}$at $m / z=535.1087$, which corresponded to the molecular formula $\mathrm{C}_{24} \mathrm{H}_{22} \mathrm{O}_{14}$. The low resolution ESIMS of 11 showed pseudomolecular ion peaks at $\mathrm{m} / \mathrm{z}=535[\mathrm{M}+\mathrm{H}]^{+}$in the positive and $533[\mathrm{M}-\mathrm{H}]^{-}$in the negative ion mode. The molecular weight of 11 was 86 mass units larger compared to that of isoorientin (9) suggesting a substitution with a malonyl group, which was also inferred from the fragment ions at $\mathrm{m} / \mathrm{z}=449$ $[\mathrm{M}-\mathrm{malonyl}+\mathrm{H}]^{+}$and 447 [M-malonyl-H] $^{-}$characteristic of a malonic acid ester [12].

In the ${ }^{1} \mathrm{H}$ and ${ }^{13} \mathrm{C}$ NMR spectra of 11 measured most signals showed signal pattern and shift values matching for isoorientin (Tables 1 and 2). Significant differences were observed for the hydroxymethylene protons (H-6"'a and H-6"b) of the glucose unit showing a downfield shift of $\sim 0.7$ and $\sim 0.45 \mathrm{ppm}$ in the ${ }^{1} \mathrm{H}$ NMR spectrum due to acylation $(\delta=4.43$ and 3.96, respectively). Acylation effects were also observed for the C-6" and C-5" carbon resonances of the glucose moiety, which were shifted downfield $(+3.7 \mathrm{ppm})$ and upfield $(-1.0 \mathrm{ppm})$ due to $\alpha$ - and $\beta$-effect of acylation, respectively. Two carbonyl carbon signals of a malonyl unit were observed at $\delta=167.0$ and 167.9. The site of acylation was also supported by a long-range correlation between the glucose H-6"a, H-6"b and the carbonyl carbon of the malonyl moiety in the HMBC experiment. The proton and carbon resonances of the methylene functionality of the malonyl unit were observed at $\delta_{\mathrm{H}}=3.31$ and $\delta_{\mathrm{C}}=41.5$ and showed correlation to each other in HSQC experiment confirm- 
ing the presence of the malonyl moiety in 11. The use of MeOD instead of DMSO- $\mathrm{d}_{6}$ as NMR solvent is less suitable, because the proton and carbon resonances for the methylene of the malonyl group can not be observed due to an overlap with the solvent signal (Tables 1 and 2). Similar observations were also reported for malonylated flavonol glycosides measured in MeOD [13]. Consequently, the structure of compound 11 was established as the previously not known 6"-O-(malonyl)-isoorientin.

HR-LSIMS of 12 showed a pseudomolecular ion $[\mathrm{M}+\mathrm{H}]^{+}$at $m / z=593.1497$ corresponding to a molecular formula of $\mathrm{C}_{27} \mathrm{H}_{28} \mathrm{O}_{15}$. Accordingly, the LR-ESIMS of $\mathbf{1 2}$ showed pseudomolecular ion peaks at $m / z=593[\mathrm{M}+\mathrm{H}]^{+}$in the positive and $591[\mathrm{M}-\mathrm{H}]^{-}$ in the negative ion mode. The ${ }^{1} \mathrm{H}$ NMR spectrum of 12 exhibited similar proton resonances for the luteolin moiety as in isoorientin (9) (Table 1). Additionally, two methylene protons resonating as $\mathrm{AB}$ systems $(\delta=$ 2.62 and $2.51, J_{\mathrm{AB}}=13.8 \mathrm{~Hz} ; 2.50$ and $2.40, J_{\mathrm{AB}}=$ $14.9 \mathrm{~Hz})$ and a methyl resonance $(3 \mathrm{H}, \delta=1.30 \mathrm{~s})$ were observed. Moreover, in the ${ }^{13} \mathrm{C}$ NMR spectrum (Table 2), six additional carbon signals were present: two carbonyls ( $\delta=172.6$ and 170.5), an oxygenated quaternary carbon $(\delta=69.0)$, two methylene $(\delta=45.4$ and 45.3) and a methyl group $(\delta=27.3)$. These observations clearly suggested that compound 12 was an ester of 3-hydroxy-3-methyl glutaric acid (HMG, dicrotalic acid). NMR data found for the acyl moiety were in good accordance with those reported for similar acylated compounds $[14,15]$. Moreover, the chirality of the acyl moiety was found to be $S$ by comparing the ${ }^{1} \mathrm{H}$ and ${ }^{13} \mathrm{C}$ NMR data of the compounds having a $(S)-3$ hydroxy-3-methyl glutaric acid moiety [16-18]. The downfield shifts observed for the C-6" $(\delta=64.1)$ as well as for the $\mathrm{H}_{2}-6$ " $(\delta=4.36$ and 3.93) resonances of the $\beta$-D-glucopyranose moiety revealed the similar esterification site as in 11. The site of esterification was also supported by a long-range correlation between the oxymethylene protons of the glucopyranose moiety $\left(\mathrm{H}_{2}-6 "\right)$ and the carbonyl carbon $(\delta=170.5)$ of the HMG moiety in the HMBC experiment. Thus, the structure of 12 was established as the new 6"-O-[(S)3-hydroxy-3-methylglutaroyl]-isoorientin.

All other isolated compounds $(\mathbf{1}-\mathbf{7})$ were identified by comparison of their physical and spectroscopic data with literature values and by comparison with authentic samples. Compound 1 was identified as chlorogenic acid (5-O-caffeoyl quinic acid) based on its ${ }^{1} \mathrm{H}$ NMR spectra measured in $\mathrm{D}_{2} \mathrm{O}$, DMSO and MeOD [19]. Compound 2 was identified as adenosine [20]. Compounds $\mathbf{3}$ and $\mathbf{4}$ were identified as L-tryptophan [21] and L-phenylalanine [22] according to their ${ }^{1} \mathrm{H}$ and ${ }^{13} \mathrm{C}$ NMR data, respectively. Compounds 5-7 were identified as aloe-emodin [23], aloe-emodin acetate [24], and chrysophanol 8-O-gentiobioside [25], respectively. Compounds 5-7 were also isolated from Kniphofia species which is also a member of Asphodelaceae like Asphodelus [24].

Investigation of the air-dried leaves of $A$. aestivus resulted in the isolation of the same compounds except acylated isoorientin derivatives $\mathbf{1 1}$ and $\mathbf{1 2}$, indicating a deacylation during the drying process.

\section{Acknowledgements}

We are very grateful to Dr. K. Mayer and Mr. J. Kiermaier (both Zentrale Analytik der Naturwissenschaftlichen Fakultät IV der Universität Regensburg) for measuring the ESI and LSI mass spectra.
[1] V. A. Matthews, Asphodelus L., in P.H. Davis (ed): Flora of Turkey and the East Aegean Islands, Vol. 8, p. 85, University Press, Edinburgh (1984).

[2] S. S. Birincioğlu, İ. Çalış, H. Avc1, B. Erdağ, Turk. J. Vet. Anim. Sci. 29, 1351 (2005).

[3] M. Adinolfi, M. C. Corsaro, R. Lanzetta, M. Parrilli, A. Scopa, Phytochemistry 28, 284 (1989).

[4] M. Adinolfi, R. Lanzetta, C.E. Marciano, M. Parrilli, A. D. Giulio, Tetrahedron 47, 4435 (1991).

[5] A. M. Rizk, F. M. Hammouda, M. M. Abdel-Gawad, Phytochemistry 11, 2122 (1972).

[6] B.-E. V. Wyk, A. Yenesew, E. Dagne, Biochem. Syst. Ecology 23, 277 (1995).
[7] K. R. Markham, V. M. Chari, ${ }^{13}$ C NMR Spectroscopy of Flavonoids, in J. B. Harborne, T. J. Mabry (eds): The Flavonoids: Advances in Research, p. 19, Chapman and Hall, London (1982).

[8] J. Peng, G. Fan, Z. Hong, Y. Chai, Y. Wu, J. of Chromatography A 1074, 111 (2005).

[9] R. T. Sherwood, M. Shamma, J.L. Moniot, J.R. Kroschewsky, Phytochemistry 12, 2275 (1973).

[10] A. J. Chulia, A. M. Mariotte, J. Nat. Prod. 48, 480 (1985).

[11] T. Ersöz, İ. Çalış, J. Garcia, A. J. Chulia, Fitoterapia LXII, 184 (1991).

[12] W. Stein, D. Zinsmeister, Z. Naturforsch. 45c, 25 (1990). 
[13] K. Kazuma, N. Noda, M. Suzuki, Phytochemistry 62, 229 (2003).

[14] E. Bedir, İ. Çalıș, R. Aquino, S. Piacenta, C. Pizza, J. Nat. Prod. 62, 563 (1999).

[15] M. A. Berhow, R. D. Bennett, S.M. Poling, S. Vannier, T. Hidaka, M. Omura, Phytochemistry 36, 1225 (1994).

[16] S. Nozoe, A. Takahashi, T. Ohta, Chem. Pharm. Bull. 41, 1738 (1993).

[17] Y. Mimaki, K. Kawashima, T. Kanmoto, Y. Sashida, Phytochemistry 34, 799 (1993).

[18] L. Garlaschelli, G. Vidari, M. Virtuani, P. Vita-Finzi, J. Nat. Prod. 58, 992 (1995).
[19] G. F. Pauli, U. Kuczkowiak, A. Nahrstedt, Magn. Res. Chem. 37, 827 (1999).

[20] P. Bednarek, J. Winter, B. Hamberger, N. J. Oldham, J. Tan, K. Hahlbrock, Planta 218, 668 (2004).

[21] G.-A. Gross, PhD Thesis (Diss. ETH Nr. 7800), Swiss Federal Institute of Technology Zurich (1985).

[22] K. Lohith, S. Divakar, J. Biotech. 117, 49 (2005).

[23] K. Danielsen, D. W. Aksnes, G. W. Francis, Magn. Res. Chem. 30, 359 (1992).

[24] E. Berhanu, E. Dagne, Planta Med. 50, 523 (1984).

[25] H. Ito, Y. Nishida, M. Yamazaki, K. Nakahara, M. Michaska-Hartwich, M. Furmanowa, E. Leistner, T. Yoshida, Chem. Pharm. Bull. 52, 1262 (2004). 